\title{
YÖK ulusal tez merkezine kayitlı e-ticaret alanında yazılan lisansüstü tezlerin bibliyometrik analizi
}

\section{Bibliometric analysis of graduate thesis written in the field of e-commerce registered to the YÖK national thesis center}

\author{
Saadet Sağtaş ${ }^{1}$ \\ Saadet Ercoşkun ${ }^{2}$ \\ 1 Dr. Öğretim Üyesi, Çağ Üniversitesi, İktisadi ve İdari Bilimler Fakültesi, Türkiye, e-mail: saadetsagtas@cag.edu.tr \\ 2 Yüksek Lisans Öğrencisi, Çağ Üniversitesi, Türkiye, e-mail: saadetercoskun@gmail.com
}

Öz

Covid-19 pandemisi, kişisel tedbirler ve ülkelerin almış olduğu uygulamalar neticesinde bireylerin internet kullanımını günlük hayatın bir parçası haline getirmiş ve e-ticarete olan ilgiyi yoğunlaştırmıştır. Bu kapsamda e-ticaretin önemi tekrar gündeme gelmiş ve araştırmacıların konuya olan ilgisini arttırmıştır. Bu çalışmanın amacı, YÖK Ulusal Tez Merkezi'nde e-ticaret alanında yazılan lisansüstü tezlerin bibliyometrik analiz yöntemi ile incelenmesidir. Araştırma kapsamına "izinli" ve işletme konulu 154 lisansüstü tez dahil edilmiştir. E-ticaret konulu lisansüstü tezler yıl, üniversite türü, örneklem yöntemleri, veri kaynakları ve analiz yöntemleri başlıklarıyla incelenmiştir. Çalışma kapsamında elde edilen sonuçlara göre, e-ticaret konulu lisansüstü tezlerin 2015 sonrası arttığı, en çok devlet üniversitelerinde yayın yapıldığı ve çoğunlukla birincil veri kaynaklarından yararlanıldığı tespit edilmiştir. Ticaret hacminin önemli bir bölümünü oluşturan e-ticaret ile ilgili literatürde yer alan çalışmaların sistematik olarak incelenmesinin ileride yapılacak araştırmalar için faydalı olacağı düşünülmektedir.

Anahtar kelimeler: E-ticaret, Ulusal Tez Merkezi, Bibliyometrik Analiz

\begin{abstract}
The Covid-19 pandemic, as a result of personal measures and practices taken by countries, has made the internet use of individuals a part of daily life and intensified the interest in e-commerce. In this context, the importance of e-commerce has come to the fore again and has increased the interest of researchers on the subject. The aim of this

Citation/Atıf: SAĞTAŞ, S. \& Ercoşkun, S. (2022). YÖK ulusal tez merkezine kayıtlı e-ticaret alanında yazılan lisansüstü tezlerin bibliyometrik analizi. Journal of Awareness. 7(1): 47-55, DOI: 10.26809/joa.7.1.04

Corresponding Author/ Sorumlu Yazar:

Saadet Sağtaş

E-mail: saadetsagtas@cag.edu.tr

Bu çalışma, Creative Commons Atıf 4.0 Uluslararası Lisansı ile lisanslanmıştır.

This work is licensed under a Creative Commons Attribution 4.0 International License.
\end{abstract}


study is to examine the postgraduate theses written in the field of e-commerce in the YÖK National Thesis Center with the bibliometric analysis method. Within the scope of the research, 154 postgraduate theses on "on leave" and business administration were included. Graduate theses on e-commerce were examined under the headings of year, university type, sampling methods, data sources and analysis methods. According to the results obtained within the scope of the study, it has been determined that postgraduate theses on e-commerce have increased after 2015, they are mostly published in state universities and mostly primary data sources are used. It is thought that a systematic examination of the studies in the literature on e-commerce, which constitutes an important part of the trade volume, will be beneficial for future research.

Keywords: E-commerce, National Thesis Center, Bibliometric Analysis

\section{GİRIŞ}

Dünya'da toplumun ve bilimin gelişiminde üniversiteler önemli bir yere sahiptir. Bilginin üretilmesi ve geliştirilmesine lisans ve lisansüstü düzeyde çalışmalar yaparak katkı sağlayan üniversiteler, bilime önemli birikimler sunmaktadır. Özellikle son yıllarda gelişen teknoloji ile yeniden şekillenen eğitim- öğretim sürecinde, örgün eğitimin yanı sıra uzaktan eğitim olanaklarının arttığı da görülmektedir. Artan üniversite ve lisansüstü programları ile lisansüstü tez sayılarında da artış meydana gelmiştir. Üniversitelerde bilginin üretilmesi lisansüstü tezler aracılığıyla ortaya çıkmakta olup (Alabaş vd., 2012) bu tezlerin incelenmesi önem teşkil etmektedir.

2019 Aralık ayından itibaren tüm dünyada etkili olan Covid-19 salgını, insanların yaşam şeklini büyük ölçüde etkilemiştir. Hijyen ve sağlık tedbirleri kapsamında fiziksel temastan kaçınan ve kalabalık ortamlarda bulunmak istemeyen tüketiciler, temel ihtiyaçlar başta olmak üzere birçok ürün ve hizmet için e-ticaret sitelerini kullanmaya yönelmiştirler. Bu süreçte 12 ülkeyi kapsayan araştırmalar pandemi döneminde e-ticaret kullanım oranının, eskiye kıyasla hızlı bir büyüme yaşadığını göstermektedir (Pantelimon, Georgesco ve Posedaru, 2020). Benzer şekilde Türkiye'de e- ticaret kullanımında önemli artışların yaşandığı görülmüştür (Doğan Şahiner ve Kurt, 2020). Yaşanılan tüm bu gelişmeler ile e- ticaret hem iş dünyası hem de akademik dünya için dikkat çekici bir alan haline gelmiştir. Bu bağlamda, ticaret hacminin önemli bir bölümünü oluşturan e-ticaret ile ilgili alan yazında yer alan çalışmaların sistematik olarak incelenmesinin, gelecek araştırmalar için faydalı olacağı düşünülmektedir.

Bibloyometri, alanyazında yer alan kaynakların istatistiksel olarak incelenmesiyle, ilgili yazının gelişimini ve ilerlemesini ortaya çıkarmayı hedefleyen bir inceleme alanıdır (Al ve Coştur, 2007). Bilimsel iletişimin sağlanmasında önemli bir yer edinen bu analiz yöntemi ile niceliksel ve niteliksel açıdan incelenen alanın değerlendirilmesi mümkün olmaktadır (Borgman ve Furner, 2002). Sosyal bilimlerde son yıllarda yaygin olarak kullanılan bibliyometrik analizlerin farklı parametreler açısından ele alındığı görülmektedir. Farklı parametrelerle detaylı olarak incelenen yazın, durum değerlendirmesi yapılmasına ve var olan eksiklerinin belirlenerek çözüm önerilerinin geliştirilmesine katkı sağlamaktadır (Yılmaz, 2017). Bu çalışmanın amacı YÖK Ulusal Tez Merkezi'nde bulunan e-ticaret konu başlıklı yüksek lisans ve doktora tezlerinin incelenmesidir. Araştırma kapsaminda 2004-2021 yılları arasındaki e-ticaret alanındaki yüksek lisans ve doktora tezleri incelenmiştir. YÖK Ulusal Tez Merkezi'nde e-ticaret anahtar sözcüğü ile tarama yapılmıştır. Tez adı, izinli ve işletme konulu 148 yüksek lisans ve 6 doktora tezine ulaşılmıştır. Çalışmaya dahil edilen 154 tez bibliyometrik analize tabi tutulmuştur. Çalışma dört bölümden oluşmaktadır. Birinci bölümde, e-ticaret ve alanyazın ile ilgili kavramsal çerçeveye yer verilmiştir. İkinci bölümde, araştırmanın yöntemi hakkındaki bilgilere yer verilmiştir. Üçüncü bölümde, bibliyometrik analiz bulguları incelenmiştir. Dördüncü bölümde ise sonuç ve öneriler yer almaktadır. 


\subsection{Kavramsal Çerçeve}

Teknolojinin gelişimiyle birlikte bilişim teknolojilerinde yaşanılan hızlı gelişmeler, e- ticaret kavramının gelişmesine katkı sağlayan önemli unsurlar arasında yer almaktadır. Özellikle son yıllarda akıllı telefonlar aracilığıly her an her yerde ulaş1labilir olan internet, günlük yaşam tarzlarının yanında iş yapma biçimlerini de etkilemiştir. En genel tanımı ile internet üzerinden $\mathrm{mal} /$ hizmet alınıp satılması olan e-ticaret, gelir üretimini destekleyen tüm işlemleri de kapsamaktadır. E-ticaret, işletmelere ürün veya hizmete yönelik talep oluşturulmasından, satış sonrası müşteri hizmetlerinin sunulmasına kadar tüm süreçleri çevirimiçi olarak yürütme imkânı sağlamaktadır (Fayyad vd., 2020). Bu bağlamda e-ticaret, çevirimiçi olarak pazarlama, sipariş, ödeme ve çevirimiçi ürün veya hizmetler için dağıtım faaliyetlerini de kapsayarak (Jelassi vd., 2014) fiziksel sınırları ortadan kaldırmaktadır.

E-ticaret, işletmelere ve tüketicilere sağlamış olduğu avantajlar ile benzeri görülmemiş bir büyüme eğilimi göstererek geleneksel ticaretin yerini almıştır. Tüketiciler açısından; istenilen ürün ve hizmetin istenilen yer ve zamanda alınması, daha kaliteli ürünlerin daha ucuza alınması, ürüne daha hızlı ulaşma ve ürün hakkında daha fazla bilgi alarak kıyaslama yapma gibi avantajlar sağlamaktadır (Olcay, 2006). İşletmelere sağlamış olduğu avantajları ise; doğrudan tüketiciye ulaşma, kısa sürede daha geniş ulusal pazarlara erişim ve maliyetleri düşürme şeklinde sıralamak mümkünüdür (Hanna, 2016). E-ticaret ile global pazarlarda yer alan ürünlere ulaşma kolaylığı ve bu ürünlere ait bilgilere hızlı erişim, üreticilerin yeni pazarlara dahil olmasını da kolaylaştırmaktadır (Yüksek, 2020).

Alan yazında e-ticaretin taraflar ve kurumlar aç1sindan farklı sinıflandırmalarının yapılmasına karşın en yaygın kullanılan e-ticaret türleri; B2B (işletmeden- işletmeye), B2C (işletmeden tüketiciye) ve özellikle son yıllarda artış gösteren C2C (tüketiciden- tüketiciye) olduğu görülmektedir (Sağtaş ve Gülmez, 2019). E-ticaretin en yaygın şekli olarak bilinen B2B, işletmeler arasında yapılan mal veya hizmet aktarımı ile gerçekleşen ticaret türüdür. Başka bir ifade ile B2B e-ticaret; üretici, toptancı ve perakendeci arasında gerçek- leşen elektronik işlemleri kapsamaktadır. İşletmelerin sanal mağaza ve web siteleri aracılığıyla doğrudan tüketicilere ulaştığ 1 e- ticaret modeli olarak tanımlanan B2C, yaygınlaşan akıllı telefon ve internet kullanımı ile hızlı bir büyüme göstermiştir. İşletmeler, B2C aracılığıyla, hızlı tüketim ürünlerinden otomobile kadar geniş yelpazede ürünleri nihai tüketiciye ulaştırmaktadır (Turban vd., 2010). Özellikle geleneksel ticarete göre daha ucuz maliyet fırsatı sunan B2C e-ticaret, perakendeciler arasında rekabetçi fiyatların oluşmasına da imkân sağlamaktadır. Tüm alışveriş sürecinin elektronik ortamda ve hızlı bir şekilde gerçekleştiği BC2, sipariş planlama, fiyatlandırma, sipariş ve ödeme süreci ve teslimatı kapsayan süreçlerden oluşmaktadır (Kumar ve Raheja, 2012). B2C yalnızca ürün satın alma sürecinde değil hizmet satın alma sürecinde de aktif olarak kullanılmaktadır. Yaygın olarak kullanılan banka ve kredi hizmetleri, sağlık hizmetleri ve seyahat hizmetleri B2C e-ticaret uygular1 arasında yer almaktadır (Avc1, 2021). C2C e-ticaret, en genel anlamda iki tüketicinin birbirleri ile doğrudan elektronik ortamda alışveriş yapması olarak tanımlanmaktadır (Nanehkaran, 2013). $\mathrm{Bu}$ ticaret türünde satıcl; sosyal medya sayfası, web sitesi veya sanal mağaza aracılığıyla ulaştırabildiği gibi aracı işletmeleri de kullanabilmektedir. Aracı elektronik ticaret siteleri, alıcı ve satıc1 konumundaki tüketicileri bir araya getirmekte ve alışveriş sürecini kolaylaştırmaktadır.

Covid-19 döneminde sağllk ve bulaş önleme tedbirleri kapsamında, uygulanan zorunlu kısitlamalar ve sosyal mesafe kuraları, tüketicilerin davranışlarının önemli ölçüde değişmesine ve e-ticarete yönelmesine neden olmuştur. Tüketiciler bu dönemde fiziksel teması azaltmak ve ihtiyaçlarını karşılamak için en pratik alışveriş yöntemi olan e-ticareti kullanmış ve e-ticaret hacmi hızlı büyüme göstermiştir (Güven, 2020). 2021 verilerine göre dünya genelinde e-ticaret pazarı bir önceki yıla göre \%25,7 oranında büyüme göstermiştir (Wearesocial, 2021). Yaşanılan bu gelişmeler ile e-ticaret, hem akademik hem de iş dünyası için dikkat çeken bir alan oluşturmaktadır. Değişen koşullar ve tüketici davranışları bağlamında, alan yazında yer alan e-ticaret çalışmalarının sistematik olarak incelenmesinin, bu alanda yapılacak gelecek çalışmalar için yol 
gösterici olacağ1 düşünülmektedir.

\section{YÖNTEM}

\subsection{Araştırmanın Amacı}

Bu çalışmanın amacı YÖK Ulusal Tez Merkezi'ne kayıtlı, e-ticaret konu başlıklı lisansüstü tezlerin bibliyometrik analiz yöntemi ile incelenmesidir. Araştırmada, 2004-2021 yılları arasındaki e-ticaret alanında yayınlanan yüksek lisans ve doktora tezleri incelenmiştir. YÖK Ulusal Tez Merkezi'nde doktora ve yüksek lisans tezleri için e-ticaret tarama terimi, tez ad 1 ve izinli arama yapılmıştır. Toplam 14 doktora tezine ulaşılmıştır. İşletme konulu tezlerin filtrelenmesinden sonra toplam 6 doktora tezi araştırma kapsamına dahil edilmiştir. Aynı yöntemle yüksek lisans tezi taraması yapılmış ve 309 yüksek lisans tezine ulaşılmıştır. İşletme konulu filtrelemeden sonra araştırma kapsamına 148 yüksek lisans tezi dahil edilmiştir. E-ticaretin, Covid-19 salgını döneminde öneminin artmasıyla bu alanda çalışan tez öğrencilerine ve araştırmacılara fayda sağlaması hedeflenmektedir.

Bu çalışmada aşağıdaki sorulara yanıt aranmaktadır:

E-ticaret alanında yazılan lisansüstü tezlerin üniversite türleri (vakıf, devlet) nelerdir?

E-ticaret alanında yazılan lisansüstü tezlerin yıllar içindeki dağılımı nedir?

E-ticaret alanında yazılan lisansüstü tezlerde hangi örnekleme yöntemleri kullanılmıştır?

E-ticaret alanında yazılan lisansüstü tezlerin veri kaynakları nelerdir?

E-ticaret alanında yazılan lisansüstü tezlerin analiz yöntemleri nelerdir?

\subsection{Araştırmanın Örneklemi}

Araştırmanın evrenini YÖK Ulusal Tez Merkezine kayıtlı e-ticaret alanındaki lisansüstü tezler oluşturmaktadır. Araştırmanın örneklemini ise, e-ticaret alanında 2004-2021 yılları arasındaki erişime açık ve işletme konulu yüksek lisans ve doktora tezleri oluşturmaktadır.

\subsection{Araştırmanın Kısıtlılıkları}

YÖK Ulusal Tez Merkezi'nde bulunan "izinli" tezlerin dahil edilmesi ve erişime kapalı tezlere ulaşılamaması araştırmanın temel kısıtlılığıdır. Araştırmanın verilerine 16.12.2021-25.12.2021 tarihleri arasında ulaşılmıştır. Araştırılan tarihler arasında ulaşılan tezleri içermesi ve bu tarihten sonra eklenen tezleri kapsamaması diğer bir k1sitliliktır.

\subsection{Araștırmanın Yöntemi}

Araştırmada bibliyometrik analiz yöntemi kullanılmıştır. YÖK Ulusal Tez Merkezi'ne kayıtlı, yüksek lisans ve doktora olmak üzere toplam 154 adet izinli tez veri tarama yöntemi ile incelenmiştir. Elde edilen verilere SPSS 25.0 programı ile frekans analizi yapılmıştır.

\section{BULGULAR}

Çalışmanın bu bölümünde araştırma kapsamına dahil edilen lisansüstü tezlerin üniversite türlerine göre dağılımları, yayınlandığı üniversiteler, örneklem yöntemleri, veri türleri, yıllara göre dağılımı ve analiz yöntemleri yer almaktadır.

Tablo 1 incelendiğinde, e- ticaret konulu doktora $(\% 83,3)$ ve yüksek lisans $(\% 61,5)$ tezlerinin çoğunluğunun devlet üniversitesinde yayınlandığ1 görülmektedir. Her iki türde en az vakıf üniversitelerinde yayın yapılmıştır.

Tablo 1. Tezlerin Bağlı Oldukları Üniversitelere Göre Dağılımları

\begin{tabular}{|c|c|c|c|}
\hline Tez Türü & Üniversite Türü & Frekans (n) & Yüzde (\%) \\
\hline \multirow{3}{*}{ Doktora } & Devlet & 5 & 83,3 \\
\cline { 2 - 4 } & Vakıf & 1 & 16,7 \\
\cline { 2 - 4 } & Toplam & 6 & 100 \\
\hline \multirow{3}{*}{ Yüksek Lisans } & Devlet & 91 & 61,5 \\
\cline { 2 - 4 } & Vakıf & 57 & 38,5 \\
\cline { 2 - 4 } & Toplam & 148 & 100,0 \\
\hline
\end{tabular}


Şekil 1. Lisansüstü Tezlerin Yayınlandığı Üniversiteler

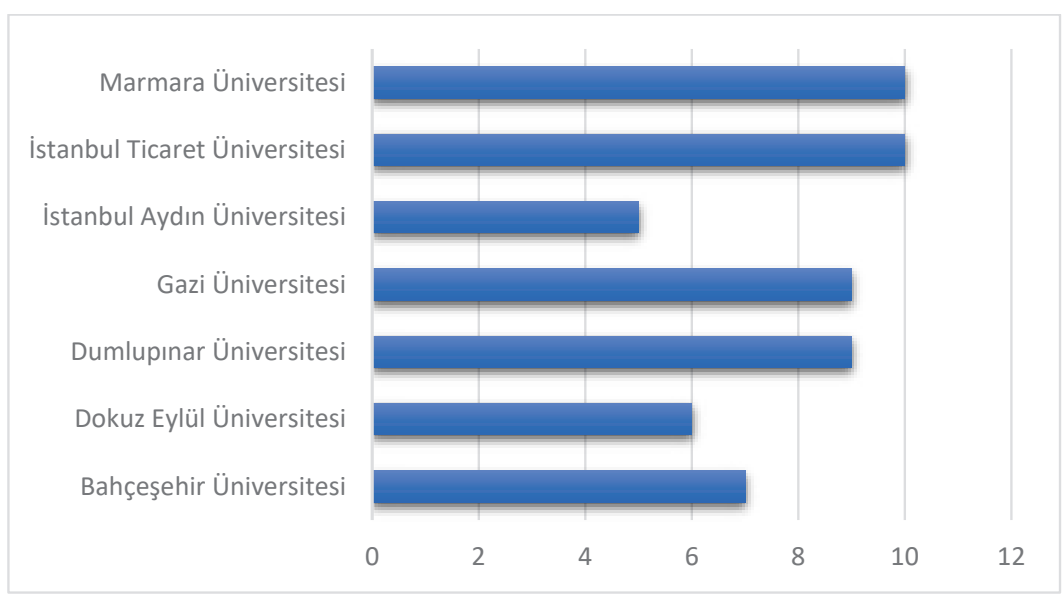

Araştırmaya dahil edilen 154 lisansüstü tez toplamda 69 üniversitede yayınlanmıştır. Şekil 1'de en çok lisansüstü tez yayınlanan üniversiteler yer almaktadır. Devlet üniversiteleri arasında en çok tez yayınlanan üniversite Marmara Üniversitesi'dir. Vakıf üniversiteleri içinde en çok tez yayınlanan üniversite ise İstanbul Ticaret Üni- versitesi'dir.

Tablo 2'ye bakıldığında, yüksek lisans tezlerinin en çok 2017-2021 yılları arasında yayınland1ğ1 tespit edilmiştir. En az yüksek lisans tezi ise 2004-2009 yılları arasında yayınlanmıştır. Şekil 2 incelendiğinde, e-ticaret konulu doktora tezleri-

Tablo 2. Tezlerin Yıllara Göre Dağılımlarının Frekans Analizi

\begin{tabular}{|c|c|c|c|}
\hline \multirow{2}{*}{ Tez Türü } & Yıllar & $\begin{array}{c}\text { Frekans } \\
\text { (n) }\end{array}$ & Yüzde (\%) \\
\hline \multirow{3}{*}{ Doktora } & $2015-2021$ & 6 & 100,0 \\
\cline { 2 - 4 } & Toplam & 6 & $100 \%$ \\
\hline \multirow{3}{*}{$\begin{array}{c}\text { Yüksek } \\
\text { Lisans }\end{array}$} & $2004-2009$ & 18 & 12,3 \\
\cline { 2 - 4 } & $2010-2016$ & 46 & 31 \\
\cline { 2 - 4 } & $2017-2021$ & 84 & 56,7 \\
\cline { 2 - 4 } & Toplam & 148 & $100 \%$ \\
\hline
\end{tabular}

Şekil 2. Lisansüstü Tezlerin Yıllara Göre Dağılımları

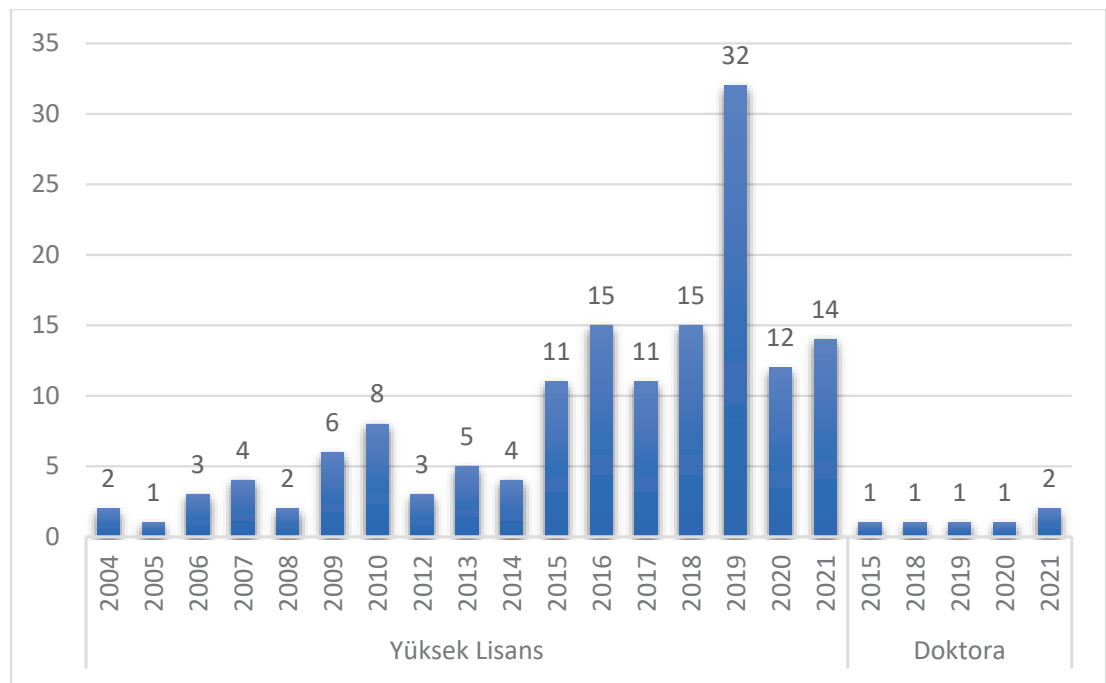


nin en çok 2021 yılında yayınlandığı görülmektedir. Yüksek lisans tezleri en çok 2019 yılında, en az ise 2005 yılında yayınlanmıştır. Ayrıca e-ticaret konulu yüksek lisans tezlerine 2015 yılından sonra yoğunluk verildiği görülmektedir.

Tablo 3 incelendiğinde, doktora tezlerinin çoğunluğunun birincil (anket, gözlem, görüşme, odak grup) kaynaklardan yararlanılarak yazıldığ1 görülmektedir. Yüksek lisans tezleri incelendiğinde en çok kullanılan veri kaynağı birincil kaynaktır. İkincil kaynaklar (şirket içi belge/ bilgi, araştırma şirketleri, kâr amacı gütmeyen kuruluşlar, devlet kurumları) ise en çok yararlanılan ikinci veri kaynağıdır.

Tablo 4'te doktora tezlerinin çoğunluğunun olasılıklı olmayan örneklem yöntemi (kolayda, amaçlı, kota, kartopu, aykırı) ile yazıldı̆̆ı görülmektedir. Yüksek lisans tezlerinde ise çoğunlukla örneklem yöntemi belirtilmemiştir. En çok kullanılan ikinci yöntemi ise olasılıklı olmayan örneklem yöntemidir. En az kullanılan iki yöntem ise ana kütlenin tamamı/tam sayım ve olasılıklı örnekleme (basit tesadüfi, sistematik, tabakalı, kümeli) yöntemleridir.

Tablo 3. Tezlerin Veri Kaynaklarının Frekans Dağılımları

\begin{tabular}{|c|c|c|c|}
\hline Tez Türü & Veri Kaynakları & Frekans (n) & Yüzde (\%) \\
\hline \multirow{3}{*}{ Doktora } & Birincil & 4 & 66,7 \\
\cline { 2 - 4 } & İkincil & 2 & 33,3 \\
\cline { 2 - 4 } & Toplam & 6 & 100,0 \\
\hline \multirow{3}{*}{ Yüksek Lisans } & Birincil & 107 & 72,3 \\
\cline { 2 - 4 } & İkincil & 38 & 25,7 \\
\cline { 2 - 4 } & İkisi birlikte & 3 & 2,0 \\
\cline { 2 - 4 } & Toplam & 148 & 100,0 \\
\hline
\end{tabular}

Tablo 4. Tezlerin Örneklem Yöntemlerinin Frekans Dağılımları

\begin{tabular}{|c|l|c|c|}
\hline Tez Türü & \multicolumn{1}{|c|}{ Örneklem Yöntemleri } & Frekans (n) & Yüzde (\%) \\
\hline \multirow{4}{*}{ Doktora } & Olas1lılı olmayan örneklem yöntemi & 3 & 50,0 \\
\cline { 2 - 4 } & Belirtilmemiş & 1 & 16,7 \\
\cline { 2 - 4 } & Yok & 2 & 33,3 \\
\cline { 2 - 4 } & Toplam & 6 & 100 \\
\hline Yüksek Lisans & Olasılıklı̈ örneklem yöntemi & 9 & 6,1 \\
\cline { 2 - 4 } & Olasıl1klı olmayan örneklem yöntemi & 46 & 31,1 \\
\cline { 2 - 4 } & Ana kütlenin tamami/tamsayımı & 3 & 2,0 \\
\cline { 2 - 4 } & Belirtilmemiş & 54 & 36,5 \\
\cline { 2 - 4 } & Yok & 36 & 24,3 \\
\cline { 2 - 4 } & Toplam & 148 & 100,0 \\
\hline
\end{tabular}


Tablo 5 incelendiğinde, yayınlanan doktora tezlerinin analiz yöntemlerinde en çok güvenilirlik analizi, ki-kare testi ve t-testinden yararlanılmıştır. Yüksek lisans tezlerinde en çok kullanılan analiz yöntemleri güvenilirlik, faktör analizi, ANOVA, t-testi, regresyon analizi ve kolerasyon analizidir.

\section{SONUÇ VE ÖNERILER}

Bu çalışmada YÖK Ulusal Tez Merkezi'ne kayıtlı lisansüstü tezlerin bibliyometrik incelemesi yapılmıştır. Araştırma, 16 Aralık 2021 ve 25 Aralık 2021 tarihleri arasında YÖKTEZ'de kayıtlı e-ticaret alanında yayınlanan lisansüstü tezleri kapsamaktadır. İzinli ve işletme konulu toplam 154 tez araştırma kapsamına alınmıştır. Araştırma kapsamında incelenen lisansüstü tezlerin çoğunluğunun devlet üniversitelerinde yayınlandı $\breve{g}_{1}$ görülmektedir. Devlet üniversiteleri arasında en çok yayın yapan üniversite Marmara Üniversitesi'dir. Yaman ve diğerleri (2018) çalışmalarında e-ticaret konulu lisansüstü tezlerin en çok Marmara Üniversitesi'nde yayınlandığını belirtmişlerdir. Bu açıdan Yaman ve diğerleri (2018) ile çalışma aynı doğrultudadır. Yüksek lisans tezlerinin 2015 yılından sonra sayısının arttı̆̆ ve 2010 yılında konuya dair lisansüstü tez yayınlanmadığ1 tespit edilmiştir. Araştırmada elde edilen bulgulara göre lisansüstü tezlerde çoğunlukla birincil kaynaklardan yararlanıldığı görülmek-

Tablo 5. Lisansüstü Tezlerin Analiz Yöntemlerinin Frekans Analizi

\begin{tabular}{|c|c|c|c|}
\hline Tez Türü & Analiz Yöntemi & Frekans (n) & Yüzde (\%) \\
\hline \multirow{12}{*}{ Doktora } & Faktör Analizi & 1 & 6,25 \\
\hline & T-testi & 2 & 12,5 \\
\hline & Ki-kare Testi & 2 & 12,5 \\
\hline & Güvenilirlik Analizi & 3 & 18,75 \\
\hline & Yapısal Eşitlik Modeli & 1 & 6,25 \\
\hline & ANOVA & 1 & 6,25 \\
\hline & Mann-Whitney U Testi & 1 & 6,25 \\
\hline & Kruskal Wallis H Testi & 1 & 6,25 \\
\hline & Tukey Testi & 1 & 6,25 \\
\hline & Lojistik Regresyon & 1 & 6,25 \\
\hline & İçerik Analizi & 1 & 6,25 \\
\hline & Diğer & 1 & 6,25 \\
\hline \multirow{16}{*}{ Yüksek Lisans } & Faktör Analizi & 40 & 12,4 \\
\hline & Kolerasyon Analizi & 25 & 7,8 \\
\hline & Regresyon Analizi & 33 & 10,2 \\
\hline & Güvenilirlik Analizi & 68 & 21,1 \\
\hline & Yapısal Eşitlik Modeli & 10 & 3,1 \\
\hline & ANOVA & 39 & 12,1 \\
\hline & Mann-Whitney U Testi & 7 & 2,2 \\
\hline & Kruskal Wallis H Testi & 8 & 2,5 \\
\hline & T-testi & 34 & 10,6 \\
\hline & Ki-kare Testi & 14 & 4,3 \\
\hline & Tukey Testi & 5 & 1,6 \\
\hline & Betimsel Analiz & 2 & 0,6 \\
\hline & İçerik Analizi & 6 & 1,9 \\
\hline & Diğer & 26 & 8,1 \\
\hline & Kümeleme Analizi & 2 & 0,6 \\
\hline & Lojistik Regresyon & 3 & 0,9 \\
\hline
\end{tabular}


tedir. Yüksek lisans tezlerinin çoğunluğunda örneklem yöntemi belirtilmemiştir. Belirtilen örneklem yöntemleri arasında olasılıklı olmayan örneklem yöntemi ise en çok tercih edilen yöntemdir. Doktora tezlerinde güvenilirlik analizi, t-testi ve ki-kare testi en çok yararlanılan araştırma yöntemidir. Yüksek lisans tezlerinde ise en sık kullanılan araştırma yöntemleri güvenilirlik, faktör analizi, ANOVA, t-testi, regresyon analizi ve kolerasyon analizidir. Ayrıca çalışmada 28 adet lisansüstü tezin literatür taraması yöntemiyle yayınlandığı belirlenmiştir.

Çalışmada e-ticaret konulu lisansüstü tezler yıl, üniversite türü, örneklem yöntemleri, veri kaynakları ve analiz yöntemleri başlıklarıyla incelenmiştir. İçinde bulunulan Covid-19 pandemi sürecinde, sadece Covid-19 pandemisi dahil edilerek ve ileride YÖKTEZ'de erişime açılan lisansüstü tezler ile farklı başlıklar altında daha kapsamlı bir değerlendirme yapılabilir. Araştırmanın konu ile ilgilenen lisansüstü öğrencilere ve akademisyenlere faydalı olacağ 1 düşünülmektedir.

\section{KAYNAKÇA}

ALABAŞ, R., KAMER, S. T., \& POLAT, Ü. (2012). Öğretmenlerin kariyer gelişimlerinde lisansüstü eğitim: Tercih sebepleri ve süreçte karşılaştıkları sorunlar/ E-Uluslararası Ë̆̈itim Araştırmaları Dergisi, 3(4), 89-107.

AL, U., \& COŞTUR, R. (2007). Türk Psikoloji Dergisi'nin bibliyometrik profili. Türk Kütüphaneciliğii, 21(2), 142-163.

AVCI, İ. (2021). Tüketiciden tüketiciye elektronik ticarette (c2c) çevrimiçi ikinci el ürün satın alma motivasyonlarının sürdürülebilir tüketim davranışı ve çevrimiçi tekrar satın alma niyeti üzerindeki etkileri ve elektronik ağızdan ağıza pazarlamanın aracılık rolü. (Doktora Tezi), Gümüşhane Üniversitesi.

BORGMAN, C. L., \& FURNER, J. (2002). Scholarly communication and bibliometrics. Annual Review Of Information Science And Technology, 36(1), 1-53.

DOĞAN ŞAHINER, D. \& KURT, Ö. (2020). E-ticaret sektöründe yaşanan gelişmeler ve tüketiciler nezdinde meydana gelen problemlerin Covid-19 kapsamında değerlendirilmesi. 20.12.2021 tarihinde Kilinclaw: https://www.kilinclaw.com.tr/koronavirus-eticaret-sektoru-hukuki-gelismeler adresinden alınmıştır.

FAYYAD, S., ALMARAHLEH, G., KLOUB, N., AWAD, A. \& RAWASHDEH, M. (2020). E-Commerce and e-technology contribution in engineering and scientific laboratories equipments contracts at Jordanian Universities, Management Studies, Vol: 8(1), 20-26.

GÜVEN, H. (2020). Covid-19 sürecinde e-ticaret sitelerine yöneltilen müşteri şikâyetlerinin incelenmesi. Electronic Turkish Studies, 15(4).511-530.

HANNA, N. K. (2016). E-commerce as a techno-managerial innovation ecosystem: Policy implications. Journal of Innovation Management, 4(1), 4-10.

JELASSI, T., ENDERS, A. \& MARTINEZ-LOPEZ, F.J. (2014). Strategies for e-business creating value through electronic and mobile commerce concepts and cases. UK: Pearson education Limited.

KUMAR, V. \& RAHEJA, G. (2012). Business to business (B2B) and business to consumer (B2C) management. International Journal of Computers \& Technology, 3(3), 447-451.

NANEHKARAN, Y.A. (2013). An introduction to electronic commerce. International Journal of Scientific $\mathcal{E}$ Technology Research, 2(4), 190-193.

OLCAY, D. (2006). E-Ticaretin temelleri. İstanbul: Pusula Yayıncilık.

PANTELIMON, F. V., GEORGESCU, T. M. \& POSEDARU, B.S. (2020) The impact of mobile e-commerce on GDP: A Comparative Analysis between Romania and Germany and how Covid-19 Influences the eCommerce Activity Worldwide, Inform. Econ., 2 (24), pp. 27-41.

SAĞTAŞ, S. \& GÜLMEZ, M. (2019). Tüketiciden tüketiciye (c2c) e-ticaret uygulamalarında alıcı ve satıcıların etik karar alma sürecini belirleyen faktörler: Türk ve Alman üniversite öğrencileri üzerine bir uygulama. Gençlik Araştırmaları Dergisi, 7(18), 147-170.

TURBAN, E., LEE, J., KING, D., \& CHUNG, H. M. (2000). Electronic commerce: A managerial perspective Prentic Hall, New Jersey.

UZUNOĞLU, H. (2002). Elektronik ticaretin vergilendirilmesinin incelenmesi ve değerlendirilmesi. (Yüksek Lisans Tezi), Gazi Üniversitesi.

WEARESOCIAL, 2021. Digital 2021 global overview report. https://wearesocial.com/uk/blog/2021/01/digital-2021-uk/ adresinden 02.01.2022 tarihinde alınmıştir.

YILMAZ, G. (2017). Ulusal turizm kongrelerinde gastronomi ve mutfak sanatları alanı ile ilgili yayınlanan 
bildiriler üzerine bir araştırma. Turizm \& Araştırma Dergisi, 6(1), 1-21.

YÜKSEK, C. (2020). Elektronik ticaretin gelişimi ve Türkiye'de işletmeden işletmeye (b2b) elektronik ticaret üzerine bir araştırma. (Yüksek Lisans Tezi), Ankara Üniversitesi. 